International Journal of Food Science, Nutrition and Dietetics (IJFS)

ISSN 2326-3350

\title{
Emergence Of A Quality Assurance Program For Probiotic Supplemented Foods
}

Review Article

S. Sarkar*

* Quality Assurance, Metro Dairy Limited, Barrackpore-Barasat Link Road, Subhasnagar, P.O. Neelgunj Bazar, Kolkata-700121, West Bengal, India.

\section{Abstract}

In recent year consumer's inclination towards natural and health-promoting foods have led to projection of probiotics as a new ingredient in functional food market. In absence of any worldwide regulation, probiotic containing foods available in the market are often of poor quality and did not meet the desired level of viable microorganisms, required for exhibiting health benefits. Presently, no globally accepted regulations for probiotic containing foods have been established, resulting in discrepancies in views, perception and quality of foods. In the present article an endeavor has been made to highlight the legislative views of different countries around the world regarding probiotic foods and prerequisites for identity of a product as a probiotic food have also been delineated.

Key Words: Probiotic; Health Claims; Legislation; Labeling; Quality Assurance.

\section{*Corresponding Author:}

S. Sarkar

Quality Assurance, Metro Dairy Limited, Barrackpore-Barasat Link Road, Subhasnagar, P.O. Neelgunj Bazar, Kolkata, West Bengal, India.

E-mail: drsurajitsarkar@yahoo.co.in

Received: June 12, 2013

Accepted: July 25, 2013

Published: July 26, 2013

Citation: S. Sarkar (2013) Emergence of a Quality Assurance Program for Probiotic Supplemented Foods. Int J Food Sci Nutr Diet. 2(6), 5660. doi: http://dx.doi.org/10.19070/2326-3350-1300011

Copyright: S. Sarkar 2013 This is an open-access article distributed under the terms of the Creative Commons Attribution License, which permits unrestricted use, distribution and reproduction in any medium, provided the original author and source are credited.

\section{Introduction}

In recent years, a considerable growing proneness towards natural and healthy foods has been perceived among the consumers throughout the world, projecting probiotics as a new dietary constituent for imparting health benefits. Probiotics may be defined as "live microbial food ingredient that, when ingested in sufficient quantities, exert health benefits on the consumer" [1]. More than 90 probiotic containing foods are available in the world market[2],[3] but most of them did not comply as per labeled information [4],[5],[6],[7]. Regulatory and labeling issues related to probiotics are complicated because they differ for each country[8] and status of probiotics as a component in food is currently not established on an international basis [9]. Recently, Council for Agricultural Science and Technology[10] also declared that products containing probiotic label marketed worldwide are currently not obligated to meet any standards due to absence of a legally recognized definition or a standard to identity or term them "probiotic". In absence of any regulation for probiotic foods, consumers are facing difficulties in deciding and confirming whether they are paying for the correct product. Worldwide acceptance and enforcement of a "Standard of Identity" for use of term "probiotics" would build consumer's confidence and boost for long-time sustainability of industries. Therefore it becomes necessary to review the legislative views of different countries and to standardize a quality assurance programme for an optimum and uniform quality probiotic product. Establishment of labeling and quality assurance procedures for probiotic compounds [11] and a standard for designating a product as "probiotic" which meets an acceptable level of safety and efficacy [12] are emerging. In the present endeavor, an attempt has been made to highlight the significance of viability of probiotics in various healthful products and to establish emergence of a quality assurance program for probiotics.

\section{Reasons for Emergence of a Quality Assurance Programme}

\section{Improper Labeling}

In absence of any rigid or well-defined regulatory norms, manufacturers, consumers as well as the regulatory authorities are facing problems. It has been annunciated that the biological nature, available products, claimed health benefits, safety and regulation of probiotics are important for both consumers and nutritional professionals [13]. Reviewed literature indicated that commercially available probiotic products do not comply with the label requirements [5],[6],[14],[15],[16]. Problem of labeling still exists due to adoption of different regulations and methods of analysis by different countries around the world [17]. Probiotic foods have not been properly identified, documented, manufactured under Good Manufacturing Practices or proven clinically, which lead consumers in difficulties to decide and confirm whether they are adopting the reliable product [18]. Worldwide regulations related to probiotic foods are incoherent and assay methods are inconsistent, which resulted in existence of following problems related to labeling [17].

- The number of live microbes of each strain delivered 
through the end of shelf life is often not accurately reflected on the label

- $\quad$ Microbes contained in the product are not always named in accordance with scientifically valid nomenclature

- Claims of efficacy are not always adequately substantiated

- Use of the term 'probiotic' on labels of products with no established record of a physiological (health) benefit in humans.

\section{Insufficient Technological Knowledge}

Various challenges faced by the industry during supplementation of probiotic cultures into food products and during the development of functional foods are depicted underneath.

- Type or form of probiotic that should be used

- Addition level required to have a beneficial effect

- Toxicity

- Effect of the processing steps on viability

- Determination, in the product, of the cell populations added

- Stability during storage

- Changes in sensory properties of the foods [19]

- Possible interaction amongst various probiotics employed [20]

- Viability of probiotics at the end of shelf-life of the product [21].

\section{Non-Conclusive Health Claims}

Though health benefits of probiotics have been established and recommended for application as a pharmaceutical agent but certain gaps still remains for their extensive exploitation. Health claims of probiotics are difficult to conclude as it has multiple variables such as population studied, age of patients, the microflora, strains used, dose and time schedule of administration, viability of probiotics [22], routes of administration and investigational procedures employed [23]. Further mechanism of action, optimum dose, frequency and duration of treatment for different probiotic strains have to be determined [24]. It has been denoted that health benefits of probiotics vary with different strains and therefore efficacy of one strain or species cannot be inferred from another [25]. Both generic health claims as well as product-specific health claims were analyzed with high-quality human data, especially in the form of randomized controlled trials but there was significant variability in the type and amount of scientific evidence needed to substantiate health claims across different jurisdictions [26].

It can be concluded that due to discrepancies in the health claims of probiotics and adoption of different regulations and methods of analysis by different countries around the world, establishment and enforcement of a globally accepted regulation and a quality assurance program for probiotics is emerging to obtain consistent product.

\section{Existing Regulations for Probiotics}

In Japan, standard have been developed by Fermented Milk and Lactic Acid Bacteria Beverages Association, which require a viable bifidobacteria population of $10^{7} / \mathrm{g}$ or $\mathrm{ml}$ in a product to be considered as a probiotic food [27]. Recent reports indicate two categories for "Food with Health Claims" in Japan namely "Food with Nutrient Function Claims" and "Food for Specified Health Uses" (FOSHU). Product that satisfies the standard for the mini- mum and maximum levels per daily portion usually consumed can adopt the "Food with Nutrient Function Claims" on their label. For adopting the FOSHU label, the product must contain dietary ingredients that have beneficial effects on the physiological functions of the human body, maintain and promote health, and improve health-related conditions. However, claims of disease-risk reduction are not currently allowed under FOSHU[28]. Recently, health regulatory officials are using their FOSHU system to approve human health claims on probiotic foods [29].

Presently, probiotic foods are not governed under specific European Union regulatory frameworks, however the Novel Food Regulation could be relevant in some special cases [30]. European Food Safety Authority (EFSA) has launched the European Initiatives towards a "Qualified Presumption of Safety" (QPS) concept that allows strains with established extensive testing to enter into the market without extensive testing requirement [31] such as Lactobacillus (including L. rhamnosus), Bifidobacterium and Propionibacterium (particularly P. freudenreichii ssp. shermanii) species [32]. A regulation related to nutrition and health claims, which provides opportunities to use the health claims such as disease risk reduction on foods in Europe was introduced in 2007 and will be fully implemented by January 2010. [33].

In USA, probiotic could fit into several four categories of foods described by Food and Drug Administration (FDA), however there exists no recognition for any health benefits of probiotics or culture added dairy products [34]. Probiotic supplements are not regulated FDA due to their classification as a nutritional product rather than as a pharmaceutical product [35]. Years ago in USA, health-related statements were not used on the tabels of probiotic-containing food products [36] but presently three categories of claims namely health claims, nutrient content claims and structure/function claims are being used on food and dietary supplement labels [37].

FDA has provided its "Partial List of Microorganisms and Microbial-Derived Ingredients that are used in Foods" which could be used as probiotics [38] and has approved six probiotic bacteria as new dietary ingredients: Lactobacillus casei, Lactobacillus reuteri, Lactobacillus plantarum, Lactobacillus bulgaricus, Lactobacillus paracasei and Bifidobacterium infantis [39]. FDA has further allowed probiotic bacteria, which were sold in dietary supplements before October 15, 1994 without having been the subjects of new dietary ingredient reviews and regarded them as being "grandfathered". If a supplement product contains a "new dietary ingredient" or a dietary ingredient not sold in the United States in a dietary supplement or not present in the food supply before October 15, 1994, then the manufacturer must notify the FDA atleast 75 days before marketing [10]. It is not justified to approve any probiotic culture based upon its previous performance and without evaluating its safety. National Yoghurt association (NYA) have allowed to use the "Live Active Culture Seal" for products containing $10^{8}$ viable cultures $/ \mathrm{g}$ at time of manufacture however, differentiate between lactic acid producing bacteria and probiotic bacteria or assurance of viability of cultures at end of shelf life are not furnished [40]. Probiotic products may be certified by US Pharmacacopeia to have a "USP Verified" seal after the review of manufacturing documentation, audit of manufacturing sites for GMP compliance, laboratory testing of product samples, and continuous off-the-shelf tests [17]. Scientific data to support the role of additional nutrients/ components as related to health and disease are still gathered and it is therefore not justifiable to require labeling of these nutrients / components at the present time [41]. 
According to Canadian Food and Drug Act, there is no provision in the legislation to make claims of a health, about the use or possible side effects of the product, if the product is sold as a food[42]. Canada differs from other global jurisdictions and has not established core nutritional criteria for foods carrying disease risk-reduction claims [43] and do not sell any probiotic product with health claim label [29].

In China, presently four main rules for functional food assessment exists namely functional assessment procedures, standard toxicological assessment, regulations on nutrient supplements and standard analytical methods for functional components [44].

In Republic of the Philippines, Bureau of Food and Drugs (BFAD) has approved bacterial strains of Lactobacilli, Bifidobacteria, non-pathogenic strains of Streptococcus, Sacchromyces boulardi and Bacillus causii for use as probiotics. For application of any other bacterial strains not found in the above list must be subject to demonstration of evidence of safe use as food supplement and analysis of the bacterial species found in formulation [45]. However, BFAD have not specified the species of approved bacterial strains to be used as probiotics.

It can be observed that different countries across the world have diverse legislative view for probiotic containing foods, which causes difficulties for the consumers to decide or ensure whether they are getting the ideal foods. It is not justified to allow the use of certain probiotic organisms, which have long history of safety. It is thus felt that various regulating agencies around the world should review the research data and establish guidelines for assessing probiotic foods for a consistent product all over the world.

\section{Provision Of Guidelines For Assessing Probiotic Foods}

In response to consumer interest in functional foods and their potential health benefits regulatory organizations have developed guidelines for assessing health claims on functional foods. Presently a number of organizations such as Food Agriculture Organization/World Health Organization (FAO/WHO), International Dairy Federation (IDF), European Food and Feed Culture Association (EFFCA), Codex Standard for Fermented Milks (CSFM) and National Yogurt Association (NYA) have taken initiatives to suggest guidelines for probiotic containing foods [17]. As there was no international consensus on methodology to assess efficiency and safety of probiotics, a working group under FAO and WHO established a set of guidelines for examining the scientific evidence on the functional and safety aspects of probiotics in food [46]. It has been suggested that the guidelines should be the ones used as a starting point for governments to devise their own policy with regards to probiotics [10]. The "Guidelines for the Evaluation of Probiotics in Food" as suggested by FAO/WHO compiling and evaluating the scientific evidence on functional and safety aspects of probiotics are depicted underneath [46].

- Genus, species and strains of starter cultures must be identified by phenotypic and genotypic methods. Nomenclature of the bacteria must conform to the current, scientifically recognized names as per Approved Lists of Bacterial Names mentioned in International Journal of Systematic Bacteriology or Validation Lists published in the International Journal of Systematic and Evolutionary Microbiology.

- Functional characterization of the product must be deter- mined through in vitro and human studies. In vitro tests for the study of probiotic strains must include resistance to gastric acidity and bile acid resistance as revealed by adherence to mucus and/or human epithelial cells and cell lines, antimicrobial activity against potentially pathogenic bacteria, ability to reduce pathogen adhesion to surfaces, bile salt hydrolase activity and resistance to spermicides .

- Safety assessment of the product must be analyzed through in vitro and animal studies and Phase 1 (Safety) human study

- Double blind, randomized, placebo-controlled (DBPC) Phase 2 (Efficacy) human trial must be carried or through other appropriate design method with sample size and primary outcome appropriate to determine if strain/product is efficacious

- Preferably second independent DBPC study must be done to confirm results

- $\quad$ Phase 3 (Effectiveness) trial is appropriate to compare probiotics with standard treatment of a specific condition

- Phase 4 (Surveillance) trials is necessary for clinical evaluation

- Labeling contents

- Genus, species, strain designation

- Health claims

- The suggested serving size must deliver the effective dose of probiotics related to the health claims

- Minimum viable numbers of each probiotic strain at the end of the shelf-life

- Proper storage conditions

- Corporate contact details for consumer information

\section{Requirements for Probiotic Labeling}

Different agencies have laid certain criteria that will allow probiotics products to bear a quality seal. Various seal qualifying criteria laid down by International Probiotics Association and International Scientific Association for Probiotics and Prebiotics include the following:

- guaranteed minimum CFU count at the time of expiration of the product

- $\quad$ storage directions

- package lot number or production code

- clear identification of the probiotic bacteria including the strain [preferred] or at least the genus and species based on widely accepted nomenclature. If a trademarked name is used to identify the bacteria, the actual genus and species should also be included on the label.

- full contact information for the company or at least a website if label space is restricted.

- $\quad$ directions for suggested usage [47]

- $\quad$ safe

- impact on human health or physiology documented by at least one controlled study in humans of suitable size and statistical power to be considered valid by experts in the field

- product labels accurately indicate per serving or per dose levels of each probiotic microbe contained in the product through the end of shelf life

- $\quad$ any efficacy statements made on product labels or in promotional materials or websites are truthful and not misleading and are based on scientifically valid studies [17]

\section{Recommendations}

Various recommendations related to quality assurance of probiot- 
ics by various organizations and investigators are depicted below.

- Ensure that any given culture maintains the beneficial properties, the stock culture should be maintained under appropriate conditions and be checked periodically for strain identity and probiotic properties

- Viability and probiotic activity must be maintained throughout processing, handling and storage of the probiotic containing food product containing the probiotic, and verified at the end of shelf-life [9] Adoption of the definition of probiotics as Live microorganisms that, when administered in adequate amounts, confer a health benefit on the host

- Adoption of the guidelines lay down by FAO/WHO as a prerequisite for calling a bacterial strain "probiotic" [46]

- Regulatory framework to allow specific health claims on probiotic food labels, in cases where scientific evidence exists as per the guidelines

- Promotion of these guidelines at an international level

- Further development of methods (in vitro and in vivo) to evaluate the functionality and safety of probiotics [46]

- Potential probiotic strains must be identified by methods including internationally accepted molecular techniques and named according to the International Code of Nomenclature, and strains should preferably be deposited in a reputable internationally recognized culture collection

- In order to be termed a probiotic, the probiotic microorganism must be able to confer defined health benefits on the host and in the actual product vehicle that will be made available to humans.

- Need for more statistically significant efficacy data in humans

- Regulatory status of probiotics as a component in food has to be established on an international level

- Surveillance systems, including trace-back and post marketing surveillance, should be put in place to record and analyze any adverse events associated with probiotics in food

- Good manufacturing practices must be applied with quality assurance, and shelf-life conditions established, and labeling made clear to include minimum dosage and verifiable health claims. [41]

- Further extensive research are required on probiotics prior to their potential clinical application [48] [49]

- Clinical trials should be focused on multi-strain preparations of known efficacy [50]

- Regulate probiotics based on their intended use, but expand regulatory conceptualization of health benefit claims

- Adopt the use of third party verification of label claims

- Consider multiple factors when evaluating probiotics

- Use a science-based assessment of the benefits and risks of genetically engineered probiotic microbes $[10]$

\section{Conclusion}

Worldwide regulations related to probiotics are incoherent and assay techniques are inconsistent and therefore establishment and reinforcement of a quality assurance program to ensure "Standard of Identity" for adopting the label of "Probiotic" is emerging. A label should be self-explanatory and must provide scientific information regarding the species and strain of microorganisms present, viable population, anticipated shelf-life to ensure desired level of viable population, conditions of storage, the specific health claims, dose and duration of intake to achieve health benefits. Further extensive research is indicated for potential clinical application. Strict adherence to the guidelines and quality assurance program is recommended during formulation of a probiotic containing food to ensure consumers for getting an ideal food and long-term existence of probiotic food industries

\section{References}

[1]. Donor S, Gorbach SL [2006] Probiotics: their role in the treatment and prevention of disease. Expert Rev Ant. Infec Therapy 4: 261-275.

[2]. Tharmaraj N, Shah NP [2003] Selective enumeration of Lactobacillus delbrueckii ssp. bulgaricus, Streptococcus thermophilus, Lactobacillus acidophilus, bifidobacteria, Lactobacillus casei, Lactobacillus rhamnosus and propionibacteria. J Dairy Sci 86: 2288-2296.

[3]. Mortazavian AM, Ehsani MR, Mousavi SM, Reinheimer JA, Emamdjomeh $Z$, et al. [2006] Preliminary investigation of the combined effect of heat treatment and incubation temperature on the viability of the probiotic micro-organisms in freshly made yogurt. Int J Dairy Technol 59: 8-11.

[4]. Yeung PS, Sanders ME, Kitts CL, Cano R, Tong PS [2002] Species-specific iden $\neg$ tification of commercial probiotic strains. J Dairy Sci 85: 1039-1051.

[5]. Temmerman R, Scheirlinck I, Huys G, Swings J [2003] Culture-independent analysis of probiotic products by denaturing gradient gel electrophoresis. Appl Environ Microbiol 69: 220-226.

[6]. Temmerman R, Pot B, Huys G, Swings J [2003] Identification and antibiotic susceptibility of bacterial isolates from probiotic products. Int J Fd Microbiol 81: 1-10.

[7]. Drisko J, Bischoff B, Giles C, Adelson M, Rao RV, et al. [2005] Evaluation of five probiotic products for label claims by DNA extraction and polymerase chain reaction analysis. Dig Dis Sci 50: 1113-1117.

[8]. Sanders ME, Huis in't Veld J [1999] Bringing a probiotic-containing functional food to the market: microbiological, product, regulatory and labeling issues. Antonie van Leeuwenhoek 76: 293-315.

[9]. FAO/WHO [2001] Health and Nutritional Properties of Probiotics in Food including Powder Milk with Live Lactic Acid Bacteria”, Report of a Joint FAO/WHO Expert Consultation on Evaluation of Health and Nutritional Properties of Probiotics in Food Including Powder Milk with Live Lactic Acid Bacteria Amerian Cordoba Park Hotel, Cordoba, Argentina 1-4 October 2001, Food and Agriculture Organization of the United Nations World Health Organization. pp. 1-38.

[10]. CAST [2007] Probiotics: Their potential to impact human health. Issue Paper 36, Council for Agricultural Science and Technology, Ames, Iowa, pp, $1-20$.

[11]. Madsen KL [2001] The use of probiotics in gastrointestinal disease. Can J Gastroenterol 15: 817-822.

[12]. Reid G [2006] Safe and efficacious probiotics: what are they? Trends Microbiol 14: 348-352.

[13]. Lin DC [2003] Probiotics as functional foods. Nutr Clin Pract 18: 497-506.

[14]. Weese JS [2002] Microbiologic evaluation of commercial probiotics. J Am Vet Med Assoc 220: 794-797.

[15]. Elliot E, Teversham K [2004] An evaluation of nine probiotics available in South Africa. South Afr Med J 94: 121-124.

[16]. Huff BA [2004] Probiotics might not be what they seem. Can Fam Physician 50: 583-587.

[17]. ISAPP [2004] Establishing Standards for Probiotic Products: ISAPP's Role. As discussed at the 2004 ISAPP IAC meeting Copper Mountain, Colorado.

[18]. Reid G, Jass J, Sebulsky MT, McCormick JK [2003] Potential uses of probiotics in clinical practice. Clin Microbiol Rev 16: 658-672.

[19]. Champagne CP, Gardner NJ, Roy D. [2005] Challenges in the addition of probiotic cultures to foods. Crit Rev Fd Sci Nutr 45: 61-84.

[20]. Vinderola CG, Mocchiutti P, Reinheimer JA [2002] Interactions among lactic acid starter and probiotic bacteria used for fermented dairy products. J Dairy Sci 85: 721-729.

[21]. Miller CW, Nguyen MH, Rooney M, Kailasapathy K [2002] The influence of packing materials on the dissolved oxygen content of probiotic yoghurt. Pack Technol Sci 15: 133-138.

[22]. Heyman M [2000] Effect of lactic acid bacteria on diarrheal diseases. J Am Coll Nutr 19: 137-146.

[23]. Adolfsson O, Meydani SN, Russell RM [2004] Yogurt and gut function. Am J Clin Nutr 80: 245-256.

[24]. Gill HS, Guarner F [2004] Probiotics and human health: A clinical perspective. Postgrad Med J 80: 516-526.

[25]. Santosa S, Farnworth E, Jones PJ [2006] Probiotics and their potential health claims. Nutr Rev 64: 265-274.

[26]. Jew S, Vanstone CA, Antoine JM, Jones PJH [2008] Generic and ProductSpecific Health Claim Processes for Functional Foods across Global Jurisdictions. J Nutr 138: 1228-1236.

[27]. Ishibashi N, Shimamura S [1993] Bifidobacteria: Research and development in Japan. Fd Technol 47: 126, 129-130,132-134.

[28]. Yamada K, Sato-Mito N, Nagata J, Umegaki K [2008] Health Claim Evidence Requirements in Japan. J Nutr 138: 1192-1198.

[29]. Farnworth ER [2008] The Evidence to Support Health Claims for Probiotics. J Nutr 138: 1250-1254.

[30]. von Wright A [2005] Regulating the safety of probiotics-the European ap- 
proach. Curr Phar Des 11: 17-23.

[31]. EFSA [2004] Scientific Colloquium Summary Report, QPS: Qualified Presumption of Safety of microorganisms in food and feeds. European Food Safety Authority, Brussels, Belgium.

[32]. EFSA [2006] Assessment of Gram Positive Non-sporulating Bacteria with respect to a Qualified Presumption of Safety. Annex 3, European Food Safety Authority

[33]. Asp NG, Bryngelsson S [2008] Health Claims in Europe: New Legislation and PASSCLAIM for Substantiation. J Nutr 138: 1210-1215.

[34]. Berner LA, O’Donnell JA [1998] Functional foods and health claims legislation: applications to dairy foods. Int Dairy J 8: 355-362.

[35]. Harish K, Varghese T [2006] Probiotics in humans-evidence based review. Calicut Med J 4: 3.

[36]. Sanders,ME [1998] Development of consumer probiotics for the U.S. market. Br J Nutr 80: 213-218.

[37]. Hasler CM [2008] Health Claims in the United States: An Aid to the Public or a Source of Confusion? J Nutr 138: 1216-1220.

[38]. Sanders ME [1999] Probiotics. Fd Technol 53: 67-75.

[39]. USFDA-CFSAN [2001] Overview of Dietary Supple $\neg$ ments. U.S. Food and Drug Administration-Center for Food Safety and Applied Nutrition.

[40]. Sanders ME [2000] Considerations for use of probiotic bacteria to modulate human health. J Nutr 130: 384-390.

[41]. CAC [2002] Joint FAO/WHO food standards programme codex committee on nutrition and foods for special dietary uses. Twenty-fourth Session, Berlin, 4-8 November 2002, Codex Alimentarius Commission, Food and Agriculture Organization of the United Nations, World Health Organiza- tion, pp. $1-5$.

[42]. Fitzpatrick KC [2004] The role of conjugated linoleic acid in human health. Am J Clin Nutr 79: 1217-1220.

[43]. L'Abbe M R, Dumais L, Chao E, Junkins B [2008] Health Claims on Foods in Canada. J Nutr 138: 1221-1227.

[44]. Yang Y [2008] Scientific Substantiation of Functional Food Health Claims in China. J Nutr 138: 1199-1205.

[45]. BFAD [2004] Guidelines on probiotics. Bureau Circular, No. 16 s. 2004 , Department of Health, Filinvest Corporate City, Alabang, Muntinlupa City, Bureau of Food and Drugs, 26 October 2004.

[46]. FAO/WHO [2002] Guidelines for the Evaluation of Probiotics in Food. Working Group Report on Drafting Guidelines for the Evaluation of Probiotics in Food, London, Ontario, Canada, April 30 and May 1, 2002, Food and Agriculture Organization of the United Nations World Health Organization, pp.39-50.

[47]. Starling S [2008] International probiotic group establishes quality seal standards. Newsletter - Breaking News on Food \& Beverage Development, Europe, 28 March, 2008.

[48]. Ghosh S, Playford RJ [2003] Bioactive natural compounds for the treatment of gastrointestinal disorders. Clin Sci 104: 547-556.

[49]. Huebner ES, Surawicz CM [2006] Probiotics in the prevention and treatment of gastrointestinal infections. Gastroenterol Clin North Am 35: 355365.

[50]. Penner R, Fedorak RN, Madsen KL (2005) Probiotics and nutraceuticals: non-medicinal treatments of gastrointestinal diseases. Curr Opin Pharmacol 5: 596-603. 